\title{
The Current Approach to Male Patients with Lower Urinary Tract Symptoms
}

\author{
Bahadır Şahin1, (D) Haydar Kamil Çam² \\ ${ }^{1}$ Marmara University, Pendik Training and Research Hospital, Clinic of Urology, İstanbul, Turkiye \\ 2Marmara University School of Medicine, Department of Urology, Istanbul, Turkiye
}

\section{What's known on the subject? and What does the study add?}

Lower urinary tract symptoms in older men should be considered a remarkable public health issue, with significant urology outpatient clinic admissions. This study will determine the current approach of urologists to these men and will aid in the provision of a standard cost-effective clinical assessment policy.

\begin{abstract}
Objective: The goal of this study was to investigate the current daily approach of urologists for the initial evaluation of men with lower urinary tract symptoms (LUTS) in accordance with the European Association of Urology (EAU) guidelines.

Materials and Methods: An online survey was used to identify the daily practices of urologists for men over the age of 45 with LUTS. Based on the EAU guidelines, an 11-item questionnaire was created. A link to the SurveyMonkey questionnaire was sent to members of a national urology association along with an e-mail message. Moreover, the data were analysed after collecting all of the responses.

Results: Out of 1.182 urologists who received an invitation message, 166 (14.04\%) responded and completed the questionnaire. The mean age of the urologists who responded was $42.24+10.11$. More than half of the participants $(56.6 \%)$ work at centres that have a urology residency programme. Furthermore, the most commonly performed laboratory test in men with LUTS was urinalysis. Approximately $90 \%$ of urologists performed urinalysis. In addition, 84\% of participants routinely measured prostate-specific antigen in every man between the ages of 45 and 75 . In all men with LUTS, approximately half of the urologists routinely used renal function tests, urinary ultrasonography, post-void residual urine measurement, uroflowmetry, and symptom score assessment. For men with nocturia and/or storage phase symptoms, the majority of participants (69.9\%) used a bladder diary. Moreover, urologists who worked at university hospitals were found to use bladder diaries significantly more frequently in their clinical practice $(p=0.037)$.
\end{abstract}

Conclusion: We discovered that there was no clinical approach standard among urologists for men with LUTS.

Keywords: Lower urinary tract symptoms, benign prostatic hyperplasia, prostate

\section{Introduction}

Lower urinary tract symptoms (LUTS) in older men account for the majority of the urologists' work, and the presence of LUTS has a negative impact on these patients' quality of life $(1,2)$. Although benign prostatic hyperplasia (BPH) is the primary cause of LUTS in older men, a wide range of disorders, including systemic metabolic pathologies, are associated with LUTS (3). Furthermore, it is a well-known fact that aging is closely related to a higher prevalence of LUTS (2). As a result of the aging population, the cost of managing men with LUTS is constantly increasing (4). Consequently, urology associations and health authorities recommend standardized simple algorithms for evaluating these men with LUTS in order to provide a costeffective clinical approach. One of the most well-known clinical guidelines belongs to the European Association of Urology (EAU). The EAU guideline titled "Management of Non-neurogenic Male LUTS" provides a comprehensive clinical guideline for these

Correspondence: Haydar Kamil Çam MD, Marmara University School of Medicine, Department of Urology, İstanbul, Turkiye Phone: +90 2166254545 E-mail: kamilcam@hotmail.com ORCID-ID: orcid.org/0000-0002-8275-5479

Received: 16.09 .2020

Accepted: 31.12 .2021

Cite this article as: Şahin B, Çam HK. The Current Approach to Male Patients with Lower Urinary Tract Symptoms. J Urol Surg 2021;8(2):130-134.

${ }^{\circ}$ Copyright 2021 by the Association of Urological Surgery / Journal of Urological Surgery published by Galenos Publishing House. 
patients, including a stepwise clinical policy (5). This guideline outlines a straightforward standard clinical approach for men with LUTS.

According to the EAU guidelines, the initial assessment of men with LUTS includes a medical history, sexual function evaluation and a straightforward physical examination. Administration of a symptom score, urinalysis, measurement of post-void residual (PVR) urine and prostate-specific antigen (PSA) in patients if a diagnosis of prostate cancer will change the management policy are the diagnostic tools that should be performed at the initial presentation. If the initial evaluation reveals several risk factors, such as haematuria and a high PVR, all other tests, including renal function assessment and ultrasonography, are recommended.

Data on the primary approach pattern of urologists for BPH in daily practice, as well as the comparison with guidelines, are scarce and not investigated in the literature. The goal of this prospective trial was to investigate the current practices of urologists for male patients with LUTS. The concordance with the EAU guidelines was also assessed to see if there were any notable differences in the evaluation of these patients.

\section{Materials and Methods}

The current national cross-sectional study used an online selfadministered survey to identify the daily practices of urologists for men over 45 years old with LUTS in outpatient urology clinics in Turkey in 2019. Based on the EAU guidelines, a questionnaire was created. The questionnaire had 11 questions about the clinical approach and diagnostic tests for men with LUTS. A link to the SurveyMonkey questionnaire was sent to members of a national urology association (The Society of Urological Surgery) along with an e-mail message. The e-mail message made it clear that participation in the study was entirely voluntary, and consent forms were obtained electronically. Respondent urologists could skip any question or opt out at any time. At 2-week intervals, all members of the association received three e-mail reminders with the survey link. Those who responded to and completed the questionnaire were not permitted to fill another online form. The study only included a survey of urologists about their clinical attitudes, with no personal information other than age, place of employment and working duration.

\section{Statistical Analysis}

All responses were obtained using the online SurveyMonkey platform, and the data were imported into Statistical Package for the Social Sciences (SPSS) version 22.0 (SPSS Inc., Chicago, IL). The Kolmogorov-Smirnov and Shapiro-Wilk tests were used to determine the normality of the data. Categorical variables in contingency tables were created to assess variable independence using the chi-square test or Fisher's exact test. The threshold for statistical significance was set at $p \leq 0.05$.

\section{Results}

The online survey was distributed via e-mail to all the members of the Society of Urological Surgery. In terms of participation in the study, 1.182 urologists were contacted via e-mail. In the end, 166 urologists (14.04\%) responded and completed the questionnaire (Table 1).

The urologists who completed the online survey had a mean age of $42.24+10.11$. The majority of the participants (36.1\%) worked at urology departments of the university hospitals (Table 1). In addition, $20.5 \%$ of urologists worked at urology departments of the ministry of health education and research hospitals.

\begin{tabular}{|l|l|l|}
\hline \multicolumn{3}{|l|}{ Table 1. Demographic characteristics of the participants } \\
\hline & N & $\%$ \\
\hline $\begin{array}{l}\text { Response rate } \\
\text { (Participant urologists/whole group } \\
\text { receiving invitation mail) }\end{array}$ & $166 / 1182$ & 14.04 \\
\hline Mean age (+ SD) & $\mathbf{4 2 . 2 4 \pm \mathbf { 1 0 . 1 1 }}$ \\
\hline Working institution & $\mathbf{N}$ & $\%$ \\
\hline University hospital & 60 & 36.1 \\
\hline Education and research hospital & 34 & 20.5 \\
\hline State hospital & 31 & 18.7 \\
\hline Private hospital & 33 & 19.9 \\
\hline Private office or small outpatient clinics & 8 & 4.8 \\
\hline SD: Standard deviation & \multicolumn{2}{|l}{} \\
\hline
\end{tabular}

Table 2. The utilization of laboratory tests in men with LUTS

\begin{tabular}{|c|c|c|}
\hline & $\mathrm{N}$ & $\%$ \\
\hline \multicolumn{3}{|l|}{ Urinalysis } \\
\hline Every man & 153 & 92.2 \\
\hline $\begin{array}{l}\text { When there is an indication based on the medical } \\
\text { history and physical examination }\end{array}$ & 13 & 7.8 \\
\hline \multicolumn{3}{|l|}{ Prostate-specific antigen (PSA) } \\
\hline Every man between the ages of 45 and 70 & 139 & 83.7 \\
\hline Every man, regardless of the patient's age & 5 & 3 \\
\hline $\begin{array}{l}\text { When there is a family history of prostate cancer } \\
\text { and/or suspicious rectal examination }\end{array}$ & 7 & 4.2 \\
\hline $\begin{array}{l}\text { When the patients accept PSA measurement } \\
\text { after discussing the possible consequences of PSA } \\
\text { screening }\end{array}$ & 15 & 9 \\
\hline \multicolumn{3}{|l|}{ Serum renal function tests } \\
\hline Every man & 77 & 46.4 \\
\hline Never & 3 & 1.8 \\
\hline $\begin{array}{l}\text { When there is a risk (high post-voiding residual } \\
\text { urine, history of stone disease, haematuria, etc.) } \\
\text { detected after initial assessment }\end{array}$ & 86 & 51.8 \\
\hline
\end{tabular}


Consequently, $56.6 \%$ of urologists work in centres that have a urology residency programme.

Urinalysis was the most commonly performed laboratory test in men with LUTS. A total of 153 urologists (92.2\%) reported routine urinalysis for every man with LUTS. Similarly, the majority of urologists (83.7\%) routinely measured PSA levels in all men aged 45-70. In addition, 77 urologists (46.4\%) stated that they routinely measured renal function tests in all male LUTS patients. Table 2 summarizes the urologists' clinical proclivity for performing laboratory tests.

According to an assessment of current policy regarding radiological imaging techniques for men with LUTS, 84 urologists (50.6\%) performed routine urinary ultrasonography (Table 3). Only 2.4\% (4/166) of urologists requested routine transrectal ultrasonography for all men with LUTS. On the other hand, according to the EAU guidelines, approximately half of the urologists $(90 / 166,54.2 \%)$ used PVR assessment, which is a routine initial test (Table 3 ).

Uroflowmetry, as a non-invasive test, was reported to be a routine part of the initial assessment for men with LUTS by nearly half of the urologists (84/166, 50.6\%). The remaining urologists $(82 / 166,49.4 \%)$ preferred uroflowmetry in severe symptomatic cases or prior to treatment (surgery or medical) (Table 4). Almost half of the urologists (81/166, 48.8\%) used validated questionnaires to assess symptom scores as an initial test of the EAU guidelines in men with LUTS (Table 4). On the other hand, a bladder diary was never obtained by any of the 44 urologists (26.5\%). For men with nocturia and/or storage phase symptoms, the majority of participants (69.9\%) used a bladder diary (Table 4).

\begin{tabular}{|c|c|c|}
\hline & $\mathrm{N}$ & $\%$ \\
\hline \multicolumn{3}{|l|}{ PVR (post-void residual) urine } \\
\hline Every man & 90 & 54.20 \\
\hline Never & 4 & 2.40 \\
\hline $\begin{array}{l}\text { When there is an indication based on the medical } \\
\text { history and physical examination }\end{array}$ & 72 & 43.40 \\
\hline \multicolumn{3}{|l|}{ Urinary ultrasonography } \\
\hline Every man & 84 & 50.60 \\
\hline Never & 0 & 0 \\
\hline $\begin{array}{l}\text { When there is a risk (high post-voiding residual } \\
\text { urine, history of stone disease, haematuria, etc.) } \\
\text { detected after initial assessment }\end{array}$ & 78 & 47.00 \\
\hline \multicolumn{3}{|l|}{ Transrectal ultrasonography } \\
\hline Every man & 4 & 2.40 \\
\hline Never & 162 & 77.60 \\
\hline
\end{tabular}

Table 4. The utilization of specific diagnostic tools in men with LUTS

\begin{tabular}{|c|c|c|}
\hline & $\mathrm{N}$ & $\%$ \\
\hline \multicolumn{3}{|l|}{ Uroflowmetry } \\
\hline Every man & 84 & 50.6 \\
\hline $\begin{array}{l}\text { In severely symptomatic cases or before initiation of } \\
\text { the treatment (surgery or medical) }\end{array}$ & 82 & 49.4 \\
\hline Never & 0 & 0 \\
\hline \multicolumn{3}{|l|}{ Symptom score } \\
\hline Every man & 81 & 48.8 \\
\hline Never & 85 & 51.2 \\
\hline \multicolumn{3}{|l|}{ Bladder diary } \\
\hline Ever man & 6 & 3.6 \\
\hline Never & 44 & 26.5 \\
\hline In men with nocturia and/or storage phase symptoms & 116 & 69.9 \\
\hline
\end{tabular}

Table 5. The impact of the urologists' institution on the use of the bladder diary in men with LUTS

\begin{tabular}{|c|c|c|c|}
\hline & $\begin{array}{l}\text { University } \\
\text { hospital } \\
(\mathrm{N}=60) \\
\mathrm{n},(\%)\end{array}$ & $\begin{array}{l}\text { Others } \\
(\mathrm{N}=106) \\
\mathrm{n},(\%)\end{array}$ & p-value \\
\hline Every man & $3(5)$ & $3(3.8)$ & \multirow[t]{3}{*}{0.037} \\
\hline Never & $9(15)$ & 35 (33) & \\
\hline $\begin{array}{l}\text { In men with nocturia and/or } \\
\text { storage phase symptoms }\end{array}$ & $48(80)$ & 68 (64.2) & \\
\hline
\end{tabular}

Except for the bladder diary, there is no difference in the use of clinical diagnostic tools for men with LUTS among urologists based on their working environment (university hospitals vs other centres). Moreover, urologists at university hospitals were found to use bladder diaries more frequently (80\% vs $64.2 \%$ ) in their clinical practice $(p=0.037$, Table 5$)$.

\section{Discussion}

Older men with LUTS are a significant burden on urologists' daily clinical practice of urologists. These male LUTS patients are also putting a strain on urology outpatient clinics. The everincreasing aging of the population raises the cost of evaluating men with LUTS for healthcare systems $(4,6)$. Therefore, there is certainly a need for a cost-effective standard clinical evaluation policy that employs the bare minimum of diagnostic tools.

One of the topics of discussion on men with LUTS is the routine use of PSA (7). PSA may be used as a screening tool by urologists and primary care physicians for all men. It was even proposed that primary care physicians preferred routine PSA screening over urologists (8). Currently, it is generally recommended that the physician and the patient reach an agreement on PSA 
measurement after discussing the potential consequences of prostate cancer screening for men with LUTS (9). Similarly, the EAU guidelines recommend PSA measurement for men with LUTS if a prostate cancer diagnosis changes management or if it aids in the treatment and/or decision-making process (5). In contrast, the current study found that the majority of urologists (about $84 \%$ ) routinely measured PSA in every man between the ages of 45 and 70 . Moreover, 3\% of the urologists obtained PSA without taking age into account.

For men with LUTS, symptom score assessment using validated questionnaires is strongly advised $(5,10-12)$. However, our results revealed that roughly half of the urologists did not use any kind of symptom score for these men. Similarly, according to the EAU guidelines, PVR measurement is a critical diagnostic tool in the evaluation of men with LUTS (5). It is incorporated into the management algorithm and serves as an indication for additional diagnostic tools such as renal function tests and pressure flow studies. It is a simple non-invasive test that provides important information about bladder function. It was also reported that a PVR threshold of $50 \mathrm{~mL}$ has a positive predictive value of $63 \%$ and a negative predictive value of 52\% for predicting bladder outlet obstruction (13). Furthermore, in these men with LUTS, a high PVR is found to be associated with symptom progression $(14,15)$. Only about half of the urologists obtained PVR on a regular basis in their daily practice.

On the other hand, the EAU guidelines do not recommend routine urinary ultrasonography for men with LUTS (5). A radiological examination is recommended for men with a high PVR, haematuria, or a history of urolithiasis. The current study found that half of the urologists routinely performed ultrasonography.

The assessment of serum renal functions in the current trial also revealed a policy that differed from the EAU guidelines. According to some authors, men with LUTS are more likely to have hydronephrosis, renal failure and urinary retentions (15). However, the exact relation between these complications and LUTS caused by BPH is unknown (16). Therefore, the EAU recommends measuring renal function if renal impairment is suspected based on history and clinical examination, or if hydronephrosis is present, or when considering surgical treatment for male with LUTS (5). In this study, 46.4\% of urologists stated that they performed renal function tests on all men with LUTS.

Uroflowmetry is a simple non-invasive diagnostic tool used to evaluate voiding function (17). The EAU does not recommend routine uroflowmetry in all men with LUTS (5). Moreover, it can be used to track treatment progress. Then, according to the EAU guidelines, uroflowmetry can be used prior to medical or invasive treatment. According to our findings, half of the urologists performed uroflowmetry on every patient, while the other used this test prior to medical or surgical treatment.

A bladder diary is an extremely useful diagnostic tool, particularly for patients suffering from nocturia $(18,19)$. In addition, a bladder diary is the only way to diagnose nocturnal polyuria. The EAU guidelines suggest using a bladder diary to assess male with LUTS with a prominent storage component or nocturia (5). In this study, approximately 70\% of the urologists used a bladder diary, as recommended by the EAU guidelines. In addition, according to the EAU guidelines, $80 \%$ of urologists working in university hospitals used bladder diaries appropriately. This rate was significantly lower for other urologists, which was around $64 \%$.

Urinalysis was the most commonly used test, and it is also strongly recommended by the EAU guidelines. Approximately $92 \%$ of all urologists used this test on every man with LUTS on a regular basis. However, when there is an indication based on the medical history and physical examination, approximately $8 \%$ of urologists obtained this test.

Conclusively, our results of the current study showed that urologists continue to prefer laboratory tests such as PSA and renal function assessment during the evaluation of men with LUTS. One possible reason for regularly obtaining these tests is the "time constraint" at outpatient clinics. The online central system of the ministry of health is set to take 5-10 minutes for each patient. Due to time constraints, a thorough history and physical examination may be impossible. Therefore, to avoid medicolegal problems, urologists prefer to obtain routine tests such as PSA and renal function. Similarly, ultrasonography may be overused for the same reasons. The lack of a national guideline approved by the ministry of health is another possible explanation for the discrepancy between current evaluation for men with LUTS and the EAU guidelines. Another reason is that there are no regular postgraduate courses available on this issue.

\section{Study Limitations}

One of the limitations of the study was the small sample size. Despite receiving multiple invitation e-mails, only 14\% of urologists completed the online survey. The second issue is that the online survey may differ from actual clinical practice. To avoid any potential bias, personal information, including names, were withheld.

\section{Conclusion}

The results of the study clearly demonstrated that there was no standard clinical approach among urologists for men with LUTS. Furthermore, the current attitude differed from the EAU guidelines. Only half of the urologists routinely used the 
EAU-recommended symptom score and PVR assessment in the initial evaluation of men with LUTS. In contrast to the EAU recommendations, PSA, serum renal function tests and urinary ultrasonography were overused. More studies and educational models are needed to develop a standardized approach to LUTS in everyday practice.

\section{Ethics}

Ethics Committee Approval: The current national crosssectional study used an online self-administered survey to identify the daily practices of urologists for men over 45 years old with LUTS in outpatient urology clinics in Turkey in 2019.

Informed Consent: Informed consent was obtained from the participants.

Peer-review: Externally peer-reviewed.

\section{Authorship Contributions}

Concept: H.K.Ç., Design: H.K.Ç., B.Ş., Data Collection or Processing: B.Ş., Analysis or Interpretation: B.Ş., H.K.Ç., Literature Search: B.Ş., Writing: B.Ş., H.K.Ç.

Conflict of Interest: No conflict of interest was declared by the authors.

Financial Disclosure: The authors declare that they have no relevant financial.

\section{References}

1. Kupelian V, Wei JT, O'Leary MP, Kusek JW, Litman HJ, Link CL, McKinlay JB; BACH Survery Investigators. Prevalence of lower urinary tract symptoms and effect on quality of life in a racially and ethnically diverse random sample: the Boston Area Community Health (BACH) Survey. Arch Intern Med 2006;166:2381-2387.

2. Martin $S A$, Haren MT, Marshall VR, Lange $K$, Wittert GA; Members of the Florey Adelaide Male Ageing Study. Prevalence and factors associated with uncomplicated storage and voiding lower urinary tract symptoms in community-dwelling Australian men. World J Urol 2011;29:179-184.

3. Abrams $P$, Cardozo L, Fall M, Griffiths D, Rosier P, Ulmsten U, van Kerrebroeck $P$, Victor A, Wein A; Standardisation Sub-committee of the International Continence Society. The standardisation of terminology of lower urinary tract function: report from the Standardisation Sub-committee of the International Continence Society. Neurourol Urodyn 2002;21:167-178.

4. Taub DA, Wei JT. The economics of benign prostatic hyperplasia and lower urinary tract symptoms in the United States. Curr Urol Rep 2006;7:272-281.

5. Gravas S, Cornu JN, Gacci M, Gratzke C, Herrmann TRW, Mamoulakis C, Rieken M, Speakman MJ, Tikkinen KAO. EAU Guidelines on Management of Non-Neurogenic Male Lower Urinary Tract Symptoms (LUTS), incl. Benign Prostatic Obstruction (BP0) 2020. European Association of Urology
Guidelines. 2020 Edition., Vol presented at the EAU Annual Congress Amsterdam 2020. Arnhem, The Netherlands, European Association of Urology Guidelines Office, 2020.

6. Vuichoud C, Loughlin KR. Benign prostatic hyperplasia: epidemiology, economics and evaluation. Can J Urol 2015;22:1-6.

7. Loeb S. Guideline of guidelines: prostate cancer screening. BJU Int 2014;114:323-325.

8. Fowler FJ Jr, Bin L, Collins MM, Roberts RG, Oesterling JE, Wasson JH, Barry MJ. Prostate cancer screening and beliefs about treatment efficacy: a national survey of primary care physicians and urologists. Am J Med 1998;104:526-532.

9. Ito K. Prostate-specific antigen-based screening for prostate cancer: evidence, controversies and future perspectives. Int J Urol 2009;16:458464 .

10. Novara G, Galfano A, Gardi M, Ficarra V, Boccon-Gibod L, Artibani W. Critical review of guidelines for BPH diagnosis and treatment strategy. European Urology Supplements 2006;5:418-429.

11. McVary KT, Roehrborn CG, Avins AL, Barry MJ, Bruskewitz RC, Donnell RF, Foster HE Jr, Gonzalez CM, Kaplan SA, Penson DF, Ulchaker JC, Wei JT. Update on AUA guideline on the management of benign prostatic hyperplasia. J Urol 2011;185:1793-1803.

12. Bosch J, Abrams P, Cotterill N. Etiology, patient assessment and predicting outcome from therapy. Male lower urinary tract symptoms Montreal, Canada: International Consultation on Urological Diseases Male LUTS Guideline 2013:37-133.

13. Oelke M, Höfner K, Jonas U, de la Rosette JJ, Ubbink DT, Wijkstra H. Diagnostic accuracy of noninvasive tests to evaluate bladder outlet obstruction in men: detrusor wall thickness, uroflowmetry, postvoid residual urine, and prostate volume. Eur Urol 2007;52:827-834.

14. McConnell JD, Roehrborn CG, Bautista OM, Andriole GL Jr, Dixon CM, Kusek JW, Lepor H, McVary KT, Nyberg LM Jr, Clarke HS, Crawford ED, Diokno A, Foley JP, Foster HE, Jacobs SC, Kaplan SA, Kreder KJ, Lieber MM, Lucia MS, Miller GJ, Menon M, Milam DF, Ramsdell JW, Schenkman NS, Slawin KM, Smith JA; Medical Therapy of Prostatic Symptoms (MTOPS) Research Group. The long-term effect of doxazosin, finasteride, and combination therapy on the clinical progression of benign prostatic hyperplasia. N Engl J Med 2003;349:2387-2398.

15. Roehrborn CG. Alfuzosin $10 \mathrm{mg}$ once daily prevents overall clinical progression of benign prostatic hyperplasia but not acute urinary retention: results of a 2-year placebo-controlled study. BJU Int 2006;97:734-741.

16. Oelke M, Kirschner-Hermanns R, Thiruchelvam N, Heesakkers J. Can we identify men who will have complications from benign prostatic obstruction (BPO)? ICI-RS 2011. Neurourol Urodyn 2012;31:322-326.

17. Idzenga $T$, Pel JJ, van Mastrigt R. Accuracy of maximum flow rate for diagnosing bladder outlet obstruction can be estimated from the ICS nomogram. Neurourol Urodyn 2008;27:97-98.

18. Cornu JN, Abrams P, Chapple CR, Dmochowski RR, Lemack GE, Michel MC, Tubaro A, Madersbacher S. A contemporary assessment of nocturia: definition, epidemiology, pathophysiology, and management--a systematic review and meta-analysis. Eur Urol 2012;62:877-890.

19. Weiss JP, Bosch JL, Drake M, Dmochowski RR, Hashim H, Hijaz A, Johnson TM, Juul KV, Nørgaard JP, Norton P, Robinson D, Tikkinen KA, Van Kerrebroeck PE, Wein AJ. Nocturia Think Tank: focus on nocturnal polyuria: ICI-RS 2011. Neurourol Urodyn 2012;31:330-339. 